\title{
Harnessing the Potential of Community Radio in Empowering Rural Women in Malawi
}

\author{
Peter Mhagama
}

\begin{abstract}
This paper examines the extent to which community radio has the empowering and transformation potential. It draws on Nkhotakota community radio station in Malawi to analyze how community radio can empower women especially in rural areas. Although the whole of the rural population can be considered as marginalized, women are the most affected as they face marginalization in the family and village setting. Based on the data drawn from semi-structured interviews, focus group discussions, document analysis, and participant observation, the paper observes that inequality and high illiteracy rate are the major hindrances among rural women which prevent them from accessing information necessary for their improvement. This paper argues that community radio has the potential to empower women in rural areas by providing them with access to information necessary to empower and transform their lives and enable them to participate in development activities.
\end{abstract}

\section{Keywords}

Access to information, community radio, empowerment, marginalized people, women

This paper examines the potential of community radio in empowering and transforming the lives of rural women who are often more marginalized than men as a result of their considered low status but also due to lack access to information. According to Lennie and Tacchi (2013: 4), "It is particularly important to take gender issues into account in the evaluation of C4D because of the significant role women and girls play in the development process, the fact that they are often more negatively affected by inequalities and disadvantage” (Held 2006; Sterling, O’Brien, and Bennett 2009). Although, the whole of the rural population can be considered as marginalized, women are the most affected as they face marginalization in the family and village setting. For Held (2006: 89), it is the subordination of women that "has created fundamental 'hindrances to human improvements'”. This suggests that in those societies where women suffer marginalization, if opportunities can be created for them to exercise their full potential and act just like their male counterparts, it can result in significant improvements in human development. However, as a consequence of their marginalized situation, many women fail to participate in development activities which could transform their lives and that of their families. Lennie and Tacchi (2013: 65) further argue that "While the participation of women is a fundamental principle for development, it is often difficult to carry through because of gender inequalities in many societies”. This is particularly true for Africa, Malawi in particular where women's marginalized situation has seen little improvement

\footnotetext{
aUniversity of Leicester, United Kingdom

Correspondent Author:

Peter Mhagama, 67 Upper Tichborne Street, Flat 5, Leicester, LE2 1GL, United Kingdom

E-mail: petermhagama@yahoo.co.uk
} 
over the years, despite efforts to improve their status especially in rural areas. According to Sterling et al. (2009: 145), the reason for this is that "HIV (Human Immunodeficiency Virus)/AIDS (Acquired Immune Deficiency Syndrome), famine, and poverty disproportionately affect women, since they not only suffer from these conditions, but also are typically the designated caretakers and providers of others so afflicted”. The situation is especially aggravated by their lack of access to the very information that could help them mitigate or manage the problems that they face (Sterling et al. 2009: 145). In rural areas of Malawi, lack of access to information is compounded by high illiteracy rate among rural women, and this has a bearing on how they can participate in development projects. As the author is going to show later in the paper, there are more women than men who are illiterate in rural areas of Malawi. According to Panos (2005: 1), it is "low literacy levels that impede the majority of people from accessing information through the print media”. This is where community radio comes in. According to the World Association of Community Radio Broadcasters (AMARC) (1998), community radio serves a catalytic role in bringing about positive change, building vibrant communities, and mobilizing people to action by informing and giving a voice to the voiceless. This definition emphasizes the potential that community radio has in empowering community members such as raising their awareness, persuading them to participate in development activities, and enabling the voiceless to have a means to communicate and access information. Women form part of the group that is mostly marginalized, voiceless, and disadvantaged, therefore empowering them is one aspect that community radio can help with. Naaikuur and Diedong (2014: 180) argue that community radio stations "have put it high on their agenda to champion the causes of women, children, the aged, and particularly the physically challenged". Community radio can provide opportunities for the more illiterate groups of people, women in particular to have access to crucial information necessary for transforming their lives. This paper examines the potential of community radio in empowering and transforming the lives of rural women who are often more marginalized as a result of their considered low status but also due to lack of information. As Mongella (1995: 121) argues, "Improving women's status is essential if we are to move the world toward a better life for individuals". The paper specifically attempts to answer the question: To what extent does community radio have the empowering and transformation potential with particular emphasis on empowerment of rural women? The author draws upon Nkhotakota community radio station in Malawi as a case study.

\section{FEMINIST APPROACH TO WOMEN EMPOWERMENT}

Empowerment is an aspect of development which can help marginalized people especially women in rural areas to participate in development activities. The term "empowerment" has been described by several scholars in different ways. However, common in all the definitions is the urge for disenfranchised or marginalized people, wanting to transform their lives and their community, to control and influence decisions in their environment (Narayan 2002; Nair and White 1993; Dugan 2003). For example, empowerment is defined as "a multilevel construct that describes a social action process for people to gain mastery over their lives, their organizations, and the lives of their communities” (Butterfoss 2006: 326). This suggests that when people are aware of their identity, talents, and capabilities, and can translate this into action, then they can be empowered. According to Naaikuur and Diedong (2014: 179), “A main communication problem in Africa is that information is not getting to the rural marginalized and lower status population”. This can potentially cause these marginalized groups to be at risk and to be less 
empowered. Community radio can therefore help to meet the information needs of rural communities especially those that are illiterate. This information can empower rural women by raising their awareness to problems, affecting them, and finding solutions to those problems. It can also enable them to participate with confidence in development activities in their communities in which they are the beneficiaries. Therefore, participation and empowerment are two sides of the same coin, and both are necessary for development to take place. Development is used here to mean "a process by which formerly excluded and subordinate social groups not only transform their physical environment, but also gain power over their economic and political environment and over the knowledge, skills, and other resources needed to sustain this transformation” (Connell 1997: 254).

Women's participation or lack of participation in development activities and the need to empower them have been an issue of concern not only in academic debates, but also in social, cultural, economic, and political circles. In the feminist approach, the reason why women do not participate in development on an equal basis with men is mainly attributed to the women's "pre-existing, subordinate positions in the society" (Connell 1997: 254). This implies that women's subordinate position has been there for as long as men and women have coexisted and this has been passed on from generation to generation, although there is no clear justification for it. In male dominated societies, this means that men have more power and they influence most decisions thereby subordinating women. This reduces women's participation in decision-making and contribution to development. To address the situation, Cornwall (2000: 1) believes that rethinking the concept of gender might more directly address "issues of power and powerlessness that lie at the heart of both gender and development”. In other words, Cornwall is suggesting that societies should rethink the gender relations and effect structural changes that will bring women at par with men. This is both a human rights and development issue. According to Quebral (2012: 21), "The empowerment of women is now considered as a strategy not only for achieving economic development but also for advancing human rights”. One way of achieving this is to give women information to enable them make informed decisions in all aspects of their lives ranging from health, education, family planning, poverty reduction, hygiene, agriculture, and economic empowerment to participation in public life. All these are aspects of development which community radio can help address. In the Socio-Economic and Gender Analysis, development is conceptualized as "a multifaceted process of increasing not only the standards of living but also control over and definition of those standards" (Connell 1997: 254). Community radio can help define the standards of living suitable for women in rural areas and empower them to have control over those standards. In the rural areas of Malawi where lack of access to information is the norm due to illiteracy and unavailability of newspapers due to distribution problems, radio is the major source of information for the illiterate people (Berrigan 1979; Girard 2001). Access to television and internet remains unattainable in these rural areas. According to Mano (2011: 103), “In Africa, radio’s main advantage is its ability to overcome the main communication barriers on the continent”. One advantage that community radio has over mainstream media is its ability to produce and broadcast programmes which have local content and contain issues that are of interest to poor people. Localized programming is relevant and appeals to the members of the community more than national and generalized programming that appeals more to general and undefined audience (Lingela 2008). Furthermore, community radio "can be the cheapest and swiftest method of reaching rural communities and of providing some expertise where none has existed” (Berrigan 1979: 7). Using Nkhotakota community radio station in Malawi as a 
case study, this paper examines the extent to which community radio can be used to empower rural women by providing them with not only access to information but also skills and expertise necessary to improve their living standards. Although, the community radio targets all groups of people in its area of coverage, the focus of this paper is on women. As Lennie and Tacchi (2013: 4) argue, "What is evaluated in relation to women and development is important, since positive social change in women's lives consists not simply of generating income, but a sense of self-worth and the ability to make life choices, exercise voice, and influence relationships". This is an aspect of women empowerment.

\section{RESEARCH METHODS}

Data presented in this paper are drawn from a research project conducted between October 2012 and March 2013 in Malawi. The data were collected through semi-structured interviews with the deputy station manager of Nkhotakota community radio station and some key informants drawn from some NGOs (non-governmental organizations) working with the radio station in the communities. The author also conducted focus group discussions (FGDs) with the listeners of the radio station in their radio listening clubs (RLCs). These FGDs were conducted in six different RLCs in Nkhotakota. Document analysis and participant observation were other techniques used to collect data. Participant observation involved observing what goes on in the radio station in terms of programme production, presentation, and daily operations or management. As part of participant observation, the author had an opportunity to interact with and interview some selected radio practitioners such as the programme manager and production manager of the station. All the observations were recorded in a diary while all the interviews and FGDs were recorded and transcribed, and used as a resource for this study. The data were analyzed using qualitative thematic analysis.

\section{NKHOTAKOTA COMMUNITY RADIO STATION}

Nkhotakota community radio station started broadcasting in 2003 with financial assistance from UNESCO (United Nations Educational, Scientific, and Cultural Organization). It is located in Nkhotakota District and targets a population of 303,659 (the population of the district) which is mostly rural (National Statistical Office [NSO] 2008). Nkhotakota community radio station has 32 RLCs that is about 10 clubs in each of the six traditional authorities ${ }^{1}$ (TAs or senior chiefs) in the district (interview with deputy station manager, October 31, 2012). A RLC is “a community based group organized by community members themselves and uses radio programmes to facilitate development discourse within their own community” (Development Broadcasting Unit [DBU] 2000). Listening clubs are, therefore, one way of engaging people in development discourses and sharing of ideas. Members of RLCs listen to designated radio programmes, discuss the content of the programme for its merit, and then decide how to use the information in their activities.

Nkhotakota District is located 200 kilometers North West of Lilongwe, the capital city of Malawi (Republic of Malawi 2010: 1). Out of the total population of the district, $73 \%$ of the total population earn income through non-formal employment especially in the agriculture sector and $32.1 \%$ of the population lives in poverty (NSO 2012). Being a lakeshore district, most of the men in Nkhotakota earn their income from the fishing industry. The illiteracy rate for Nkhotakota District is at $15.1 \%$ (NSO 2012). In terms of gender, more women in the district (16.7\%) than men (7.4\%) are illiterate (NSO 2012). This means that more women have problems accessing information in printed form, a situation which further increases their marginalization. 
In terms of media usage, the table below summarizes how people consume different media in Nkhotakota (see Table 1).

The radio listenership figure in Table 1 represents the number of people who listen to different radio stations that can be received in Nkhotakota District. The only free television channel that beams to Nkhotakota District is the national public broadcaster MBCTV, although other stations can be viewed on Digital Satellite Television (DSTV); these channels require subscriptions. The newspaper readership figure is for those newspapers that have a national readership as there are no local newspapers in the district. The newspapers are read by those people who live at the district headquarters and some major towns in the district as distribution is limited to these areas, and it is also where the majority of literate people are found. These figures reveal that the majority of people have access to a radio, making it the major source of information for the illiterate people in the district.

In terms of telecommunication infrastructure,

Telephone, fax, radio, and e-mail are the telecommunication services which Nkhotakota District has. Telephone services include ground lines by Malawi Telecommunication Ltd. (MTL) and mobile lines by Telecom Networks Malawi (TNM) and Celtel (now Airtel). The district has two automatic telephone exchanges... The two exchanges have a combined total of 826 telephone subscribers shared among private telephones (487), private bureaus (102), institutional telephones (181), and public call booths (32). Some of these lines are also used for faxes (30) and e-mails (18). Some of the telephone lines are connected outside the cable network through radio. (Republic of Malawi 2010: 140-141)

The figures presented above indicate that very few people have access to the landlines, because there are no landlines in the rural areas due to poor road infrastructure. As Berrigan (1979: 7) observes, in developing countries, "Most people live in rural areas where transport of people and commodities is slow and difficult, cutting off access to markets, to social and cultural centers”. In Nkhotakota District, most service providers including telephone services are limited to places where there are good roads leaving most of the rural areas unattended to (Republic of Malawi 2010). As a result, it takes a long time for essential services and improvements like education and health to extend to the rural areas where the majority of the population lives (Berrigan 1979). In Nkhotakota District, messages are sent through people on bicycles or foot and sometimes by post (Republic of Malawi 2010).

In terms of the proliferation of mobile phones, at the national level,

There are more households with mobile phones than with landlines. Thirty-six percent of households reported having a mobile phone while only less than $1 \%$ of households reported having a landline telephone. Urban areas have registered having the highest proportion of household with mobile phones at $73 \%$ than in rural areas at 30\%. (NSO 2011: 123)

In Nkhotakota alone, ownership of mobile phones rose from 2.1\% in 2005 to $44.9 \%$ in 2011 (NSO 2011: 124). This is a substantial increase signifying the importance and penetration of mobile phones not only in rural areas of Nkhotakota District but also the whole country. For people in the rural areas with little access to landlines, the mobile phone can be a big boost in efforts to increase levels of access to information.

In a nutshell, the socio-economic profile, media landscape, and the telecommunication infrastructure of Nkhotakota District presented above give an impression of a situation where there is limited access to crucial information that might enhance ordinary people's living standards especially for women. Therefore, the establishment of Nkhotakota community radio station should be viewed as an important intervention to compensate for the lack of access to information due to illiteracy and also to compensate for poor communication infrastructure in 
Table 1. Media Consumption in Nkhotakota District

\begin{tabular}{lll}
\hline Media consumption & Number of people & Proportion (\%) \\
\hline Radio listenership & 285,950 & 95 \\
TV viewership & 210,750 & 70 \\
Newspaper readership & 90,300 & 30 \\
\hline
\end{tabular}

Note: Source: Nkhotakota SEP (2010).

Table 2. Proportion of Nkhotakota Listenership

\begin{tabular}{llll}
\hline Number & Name of station & Type of station & Listenership (\%) \\
\hline 1 & MBC Radio 1 & Public broadcaster (national) & 50 \\
2 & MIJ & Private broadcaster (national) & 5 \\
3 & MBC Radio 2 & Public broadcaster (national) & 41 \\
4 & ZBS & Private broadcaster (national) & 80 \\
5 & Radio Maria & Community of interest (national) & 7 \\
6 & Capital FM & Private broadcaster (national) & 2 \\
7 & Nkhotakota & Community radio & 52 \\
8 & Power 101 FM & Private broadcaster (national) & 2 \\
9 & Radio Islam & Community of interest (national) & 4 \\
10 & Transworld Radio & Community of interest (national) & 14 \\
11 & Channel for All Nations & Community of interest (national) & 4 \\
12 & SDA & Community of interest (national) & 2 \\
\hline
\end{tabular}

Note: Source: MACRA website.

the district. The table above shows how Nkhotakota community radio station fares among all the stations that can be received in the district based on a survey that was conducted by MACRA in 2012 and whose results were released in September 2013 (see Table 2).

It has been argued that "Without the best possible understanding of how community radio interacts with its target communities, the sector and individual stations within it may well be 'flying blind' and, as a result, not delivering services to best effect" (Hallett 2012: 378). With a listenership of 52\%, Nkhotakota community radio is the second most widely listened radio station in the district after ZBS. This is an indication that the station enjoys a good standing in its community and can build on this listenership to properly deliver social gain especially increasing access to information among the most of the marginalized groups of people. Organizations which champion women's rights can use the station to reach out to many disadvantaged and marginalized women in the rural areas to disseminate information that can empower them. The radio station broadcasts a number of programmes which address a number of development-related issues such as agriculture, health, education, and development projects taking place in the community.

\section{HOW COMMUNITY RADIO CAN HELP TO EMPOWER WOMEN AND IMPROVE THEIR LIVELIHOODS}

The findings show that community radio can increase the opportunity for women to access and discuss crucial information necessary for the improvement of 
their livelihoods. The organization of listeners into RLCs provides a platform to discuss and unpack development conundrums (Manyozo 2012), especially for the illiterate women. In almost all listening clubs the author visited, there were more women than men which implies that women form the majority members of these clubs. The reasons for this are varied; some have to do with gender roles, others have to do with traditional practices and other economic reasons. For example, members of some RLCs reported that men are usually busy with work and sometimes their work demands going away from home frequently. On the other hand, women remain at home most of the times, so they have time to participate in club activities where radio listening is one of the activities. For example, it was reported in one FGD that:

Being a lakeshore area, boys and men normally prefer going to the lake to fish unlike being in groups, because they make money from fishing. This explains why we have more female members in our groups, because women and girls are at home when men have gone fishing. (FGD 6, November 6, 2012)

The participants further explained that while the men are away fishing or doing other jobs, it is mostly women who are involved in farming, hence their increased interest in joining farmers clubs. The women claimed that they are always determined to succeed in implementing what they have learnt from the programmes. Women see themselves as being responsible for the upbringing of children and so if they do not work hard in the garden, then there will be no food for the children. Furthermore, because of their considered low status in society, women are said to welcome development news more positively than men so that they can improve their livelihoods through the benefits that may come through joining clubs (FGD 6, November 6, 2012).

The second reason for the gender imbalance in RLCs is that sometimes ownership of the radio set is problematic. For example, an FVR (Farmers' Voice
Radio) $)^{2}$ projects manager explained that:

Some men think that they own the radio set, so when they are going away, they take it with them so that they can listen to it when doing their daily duties. Sometimes, men hide batteries so that they can listen to their favourite programmes at their own time when they come back. This leaves women with no opportunity to listen to the radio, hence they opt to join radio listening clubs and listen to the radio in their clubs. (interview, March 16, 2013)

According to a Farm Radio International (2011: 15) report, $75 \%$ of males and $56 \%$ of females in Malawi own radio sets. Although these figures do not indicate listening habits between men and women, it can be argued that more men than women have access to a radio set. This is consistent with Moyo's (1991) study. In her feature article on Development Through Radio (DTR) in Zimbabwe, Moyo (1991: 229) reports that during district meetings in Chikwaka area, when the idea of DTR/RLCs was introduced, the women accepted the idea of forming RLCs with "great enthusiasm”, because a small number of people owned radio sets there. For example, she reports that out of 150 women present only 11 of them had working radio sets, but when nine RLCs with 35 members in each club were introduced in the area, it gave an opportunity to more than 315 people to access a radio (Moyo 1991: 229). Therefore, in their quest for information, more women join RLCs so that they can listen to a radio at the listening club. The RLCs serve to increase women's access to radio and to information necessary to improve their livelihoods.

However, unlike Manyozo (2005) who found that there was male dominance in the dialogues that characterize RLCs despite women being in the majority, the author found that when making contributions, both men and women expressed their views equally. The author observed this when conducting FGDs in the listening clubs. It can be suggested, therefore, that over the years, the RLCs have empowered women in the research area to 
participate without fear in issues that affect them. Therefore, by participating in RLCs, more women can be empowered and gain confidence to come in the open and express themselves about issues that affect them as individuals. This is also consistent with the findings of a study of "The Role of Community Radio in Livelihood Improvement: The Case of Simli Radio in Ghana”. The study found that:

As the incomes of women engaged in Income Generating Activities (IGA) have been enhanced with the help of the promotional activities of Simli Radio, there is increasing acceptance of women's views in matters that affect not only the family but the community as well. The daily programmes aired on Simli Radio have helped to "soften" the grounds for female voices to be heard... on some topical issues that affect the family and community generally. (Al-hassan, Andani, and Abdul-Malik 2011)

Therefore, RLCs can provide a forum for women not only for accessing information but also increasing their capacity to participate in democratic processes and decision-making. Such a forum can enable women to make informed decisions, to speak out their mind, and to have a voice just as their male counterparts. In this way, community radio can be said to empower women, increase opportunities for their participation, and create a forum for discussion of issues affecting them. To illustrate these issues, the participants claimed that:

Here along the lakeshore area, women were not engaging in any economic activities, only men did. These days, because of the programmes which are broadcast on the radio, women have become as active as men economically. They are now doing business just like their male counterparts. (FGD 1, November 2, 2012)

This claim can be read as meaning that the radio station has encouraged women to think about gender roles and to do something about it to reverse the situation. This claim that more and more women are now involved in small scale businesses is a sign of development as result of access to information through the community radio station. The people feel that they are informed and so their awareness has been raised, and because of this, they are motivated to change. The radio station somehow legitimizes this change. The women further claimed that they are now closing the gaps in the gender divide by contributing equally to the running of their families instead of just depending on men. The women further explain that:

As women, we were just depending on our husbands for everything. Currently, many women are farming on their own thereby benefiting their homes as well. (FGD 3, November 3, 2012)

Women's ability to contribute to the family income or food basket is indicative of "women's agency" (Sen 1999). Sen (1999: 192) argues that woman's "contribution to the prosperity of the family is then more visible, and she also has more voice, because of being less dependent on others". Alternatively, “it is women's capacity to exercise voice in the key areas of their lives that provides the impetus for change” (Kabeer 2011: 1). Community radio, therefore, can empower women by enabling them to have access to information and also to have a means to express themselves.

According to Malawi's National AIDS Commission (NAC), at national level, Nkhotakota District appears as one of the high risk districts in terms of HIV prevalence which is estimated at $12 \%$ (Republic of Malawi 2010: 74). The Nkhotakota Community Radio Station Policy Document (N.d.) states that "The station realizes the negative impact brought by the HIV/AIDS epidemic in various social economic developments in the community and it is for this reason that the station advocates raising awareness through production of various HIV/AIDS programmes". Raising awareness can help clear misunderstandings or myths regarding HIV/AIDS. This is consistent with Parker, Rau, and Peppa's (2007) argument that better understanding about HIV 
and AIDS are generated at a local level where dialogue about the epidemic leads to generation of solutions at this level, involving community-generated media. Therefore, community radio can be used as a community resource for dissemination and sharing of information which can help ordinary people to become knowledgeable about HIV/AIDS issues as discussed below.

There is a programme on Nkhotakota community radio station called $\mathrm{Pa}$ Dooko (On the Dock) which targets fishermen and fish vendors along the lakeshore to be faithful to their partners to reduce the spread of HIV/AIDS. It is reported that multiple concurrent sexual partnerships are commonplace in various fishing docks in this lakeshore district involving both men and women (interview with deputy station manager, October 31, 2012). As previously argued, the fishing industry along this lakeshore district is dominated by men, meaning that men are in control of the cash flow. Therefore, "in quest for resources, women exchange their bodies with fish, cash, and other products from the lake, hence the popular phrase of 'sex for fish, fish for sex"' (Republic of Malawi 2010: 75). This is the practice which is fueling the spread of HIV/AIDS in the district and it affects women more than men as previously argued. According to Tufte (2005), it is not lack of information but social inequality that is contributing to the spread of HIV/AIDS. However, in some rural areas in Malawi, both lack of information and social inequality are the factors contributing to the spread of HIV/AIDS. Therefore, $\mathrm{Pa}$ Dooko programme targets those people engaged in this practice by providing them with information to raise their awareness to the problem and encourage them to refrain from indulging in it. This information not only raises their awareness but also helps to build self-confidence and empowers them to have control over their environment. For example, young women claimed that the discussions which take place in RLCs have helped them to gain confidence which enables them to among other things, negotiate use of a condom during sex, as illustrated in this response:

We as girls are equipped with skills necessary to curb harassment. We can be bold and firm on the use of condoms and in addition, if one violates our rights, we know where to go and report the human rights violations. (FGD 6, November 6, 2012)

Consequently, this has the potential of reducing women's vulnerability to abuse, because the information they receive from the community radio can empower them to defend their rights by reporting abuse cases and other human rights violations. The spread of HIV/AIDS can further be reduced in the process. Therefore, instead of suffering in silence, community radio can enable marginalized people to access information to mitigate the problems that they face. This is particularly significant for people living in rural areas where there are no or very few places or organizations where abuse cases can be reported. There are also no places where people can receive counseling on the problems affecting them. Therefore, by listening to specific programmes on the community radio together and discussing problems in groups, women can enlighten one another about issues affecting them.

To illustrate this point further, members of one RLC listen to HIV/AIDS programmes such as $\mathrm{Pa}$ Dooko, discuss the programme content and educate one another on how to end the practice of "sex for fish" or "fish for sex" to prevent the spread of HIV/AIDS. The participants said: "Pa Dooko programme encourages women to refrain from risky behaviours and we also advise our husbands about HIV and AIDS" (FGD 2, November 3, 2012). The issue of "sex for fish" or "fish for sex" was highlighted as a major problem in the area as well as how Pa Dooko programme is helping with this. The women participants claimed that multiple concurrent partnerships have been reduced because of the programme, as explained below: 
We have changed through some radio programmes such as Pa Dooko. We didn't have peace of mind in our houses, but since we started listening to this radio station, we have peace of mind. Even our husbands have changed their habit of having girlfriends, because we are now doing whatever they say. This club is helping to lessen the spread of HIV/AIDS. (FGD 2, November 3, 2012)

In this excerpt, the women claim that previously they had no peace of mind, because they were always disturbed with fears that their husbands would infect them with HIV due to their promiscuous behaviours. The fear is no longer there because the programme gives these people hope as they see themselves stopping their promiscuous behaviour. This has the potential to reduce the further spread of HIV. Another radio programme called Timasukilane (Let Us Be Open With One Another) discusses marriage issues. The programme equips married couples with interpersonal communication skills to help them tackle misunderstandings in the family which arise due to poor communication. It was claimed that less men are leaving their matrimonial homes and this is helping to save marriages from breaking up and to reduce the spread of HIV/AIDS as reported below:

We have also benefited from the radio through programmes such as Timasukilane. In the past, our marriages ended unexpectedly. Men were leaving their wives and went to town; there were a lot of broken families. But with Timasukilane, the families have reconciled and men are no longer leaving their matrimonial homes. Since this programme has helped build our marriages, we make it a point not to miss it. (FGD 1, November 2, 2012)

To further exemplify this point, one woman said:

I had misunderstandings with my husband because he kept on insisting that we should go for HIV testing. After listening to radio programmes on HIV/AIDS, both of us went for testing and we are now happy because we know our status. (FGD 1, November 2, 2012)

According to Servaes (1999: 93), "Development is meant to liberate and emancipate people and, in doing so, enable them to meet their basic needs". Community radio, therefore, has the potential to raise people's awareness to existing problems through educative programmes. Through spousal communication, the radio programmes can enable them to think about these issues and do something about them. Such information and the corresponding behavior change can be liberating and emancipatory. Although, the problem of sexual promiscuity involves both men and women, in most cases, women are on the receiving end as a result of their considered low status, lack of information, and powerlessness to discuss use of condoms.

In communication for development, Quebral (2012: 14) argues, communication media can "circulate knowledge that will inform people of significant events, opportunities, dangers, and changes in the community...; teach those ideas skills and values that people need to achieve a better life". Communication for development is defined as "a strategic tool to persuade people to change and enhance development processes" (Tufte and Mefalopulos 2009: 1). To illustrate this point, one woman explained that:

What I like most is that we are taught on how best we can keep our families, how many children we should be bearing, and how best we can take care of them considering the scarcity of food that is in our midst. (FGD 4, November 4, 2012)

Such knowledge can contribute to a reduction in maternal deaths, improved family health, more care and love given to children, and enough food for the family. Such messages were not readily available to the mothers, hence the importance of community radio as a community resource for enabling access to development information. This has the potential to empower women and improve their livelihoods. Here community radio is being used as a communication strategy in a public health campaign to disseminate information about maternal health to rural women. 


\section{CONCLUSIONS}

In conclusion, the paper has examined and discussed how community radio can empower women by providing them with access to information which is a scarce resource in rural areas. The paper has demonstrated that community radio has potential to empower and transform women's livelihoods by enabling them to have access to information necessary for improving their status. Access to information can empower women and also increase their chances of participating in development activities. When community radio can be co-opted or enrolled as communication for development to disseminate information to specific target audiences such as women, it can help to raise their awareness to issues that affect them and persuade them to do something about their marginalized status. Some NGOs and development agencies whose objectives are to empower rural women, promote gender equality, and improve women's status can use community radio as their communication strategy to disseminate information about their activities for wider impact in the rural areas. This can enable women to know and defend their rights, do something about the problems affecting them such as HIV/AIDS, poverty, maternal health, etc., and also engage in economic activities to improve their livelihoods. Community radio can therefore be said to have the potential to empower marginalized groups such as women. Lennie and Tacchi (2013) warn that there is a big challenge in achieving substantial levels of participation and inclusion in situations with high levels of oppression and disadvantage, and where there are inequalities and conflicting agendas. However, despite the limited resources and gender inequality still existing, the paper has demonstrated that community radio can help increase opportunities for women participation in development activities such as farming own their own, engaging in small-scale businesses, and having control over their environment.

\section{Funding}

This research work was funded by the Commonwealth Scholarship Commission of the United Kingdom through a scholarship for the author's PhD studies.

\section{Notes}

1. There are 28 districts in Malawi. Administratively, the districts are subdivided into Traditional Authorities (TAs) presided over by senior chiefs. The TAs are composed of villages, and these are the smallest administrative units presided over by village headmen/women (NSO 2011: 13).

2. In Malawi, FVR is a consortium made up of the Ministry of Agriculture, Irrigation and Water Development (MoAIWD); Bunda College of Agriculture, a former constituent college of the University of Malawi; Centre for Alternatives for Victimized Women and Children (CAVWOC); Creative Centre for Community Mobilization (CRECCOM); Farm Radio Malawi; Malawi Broadcasting Corporation (MBC); and all community radio stations in Malawi with funding from the Bill and Melinda Gates Foundation of the USA.

\section{References}

Al-hassan, S., A. Andani, and A. Abdul-Malik. 2011. "The Role of Community Radio in Livelihood Improvement: The Case of Simli Radio.” The Journal of Field Actions 5. Retrieved January 11, 2012 (http://factreports.revues.org/ 869).

AMARC (World Association of Community Radio Broadcasters). 1998. What Is Community Radio? A Resource Guide. Lusaka: AMARC \& Panos Publishers.

Berrigan, F. J. 1979. Community Communications: The Role of Community Media in Development. Paris: UNESCO.

Butterfoss, F. D. 2006. "Process Evaluation for Community Participation.” Annual Review Public Health 27:323-340. Retrieved February 28, 2012 (http://www.annualreviews. org).

Connell, D. 1997. "Participatory Development: An Approach Sensitive to Class and Gender." Development in Practice 7:248-259.

Cornwall, A. 2000. "Making a Difference? Gender and Participatory Development.” IDS Discussion Paper 378. Brighton, England: Institute of Development Studies. Retrieved January 20, 2014 (http://www.ntd.co.uk/ idsbokshop/details.asp?id=597).

Development Broadcasting Unit (DBU). 2000. The Development Broadcasting Unit. Retrieved January 20, 2005 (http://www.mbcradios.com/aboutmbc/dbu.htm). 
Dugan, M. A. 2003. “Empowerment.” In Beyond Intractability, edited by G. Burgess and H. Burgess. Boulder: Conflict Research Consortium, University of Colorado.

Farm Radio International. 2011. Participatory Radio Campaigns and Food Security: How Radio Can Help Farmers Make Informed Decisions. Retrieved (http://www. farmradio.org/pubs/farmradioprcreport2011).

Girard, B., ed. 2001. A Passion for Radio: Radio Waves and Community. Retrieved (http://comunica.org/passion/ contents.htm).

Hallett, L. 2012. "Measuring Community Radio Audiences.” In Radio Evolution: Conference Proceedings, edited by M. Oliveira, P. Portela, and L. A. Santos. Braga: Communication and Society Research Centre, University of Minho.

Held, D. 2006. Models of Democracy. 3rd ed. Cambridge: Polity Press.

Kabeer, N. 2011. "Contextualizing the Economic Pathways of Women's Empowerment: Findings From a Multi-country Research Programme.” Pathways Policy Paper, October 2011. Brighton: Pathways of Women's Empowerment RPC.

Lennie, J. and J. Tacchi. 2013. Evaluating Communication for Development: A Framework for Social Change. Oxon: Routledge.

Lingela, M. B. 2008. "Community Broadcasting in SADC: An Overview.” Gender and Media Diversity Journal. Retrieved (http://www.genderlinks.org.za).

Mano, W. 2011. "Why Radio Is Africa's Medium of Choice in the Global Age.” Pp. 102-116 in Radio in Africa: Publics, Cultures, Communities, edited by L. Gunner, D. Liganga, and D. Moyo. Johannesburg: Wits University Press.

Manyozo, L. 2005. "The Practice of Participation in Broadcasting for Development in Post-independent Malawi." Journal of Social Development in Africa 20:77-105.

—. 2012. People's Radio: Communicating Change Across Africa. Penang: Southbound.

Mongella, G. 1995. "Moving Beyond Rhetoric.” In Women: Looking Beyond 2000. New York: United Nations Publications.

Moyo, M. 1991. "Development Through Radio: Special Feature.” Community Development Journal 26:227-232.

Naaikuur, L. and A. L. Diedong. 2014. "Core Dimensions of Community Radio in Action: The Case of Ghana.” Global Media Journal African Edition 8:175-206.

Nair, K. S. and S. White, eds. 1993. Perspectives on
Development Communication. New Delhi: SAGE Publications.

Narayan, D., ed. 2002. Empowerment and Poverty Reduction: A Sourcebook. Washington, D.C.: The International Bank for Reconstruction and Development.

National Statistical Office (NSO). 2008. Malawi Population and Housing Census Report. Zomba, Malawi.

. 2011. Welfare Monitoring Survey Report. Zomba, Malawi.

- 2012. Integrated Household Survey 2010-2011: Household Socio-economic Characteristics Report. Zomba, Malawi.

Nkhotakota Community Radio Station Policy Document. (N.d). Panos. 2005. The Broadcasting Landscape: Malawi. Lusaka: Panos.

Parker, W., A. Rau, and P. Peppa. 2007. HIV/AIDS Communication in Selected African Countries: Interventions, Responses and Possibilities. Lusaka: SIDA.

Quebral, N. C. 2012. Development Communication Primer. Penang: Southbound.

Republic of Malawi. 2010. Nkhotakota District Assembly Social Economic Profile. Nkhotakota District Council.

Sen, A. K. 1999. Development as Freedom. Oxford: Oxford University Press.

Servaes, J. 1999. Communication for Development: One World, Multiple Cultures. Cresskill, N.J.: Hampton Press.

Sterling, S. R., J. O’Brien, and J. K. Bennett. 2009. “Advancement Through Interactive Radio.” Inf Syst Front 11:145-154.

Tufte, T. 2005. "Entertainment Education in Development Communication: Between Marketing Behaviours and Empowering people.” In Communication for Social Change Anthology, edited by A. Gumucio-Dagron and T. Tufte. CFSC Consortium.

Tufte, T. and P. Mefalopulos. 2009. Participatory Communication: A Practical Guide. Washington, D.C.: The World Bank.

\section{Bio}

Peter Mhagama, MA, Ph.D. candidate, Department of Media and Communication, University of Leicester, United Kingdom, senior lecturer, Department of Language and Communication, The Polytechnic, University of Malawi, Malawi; research fields: community media, communication for development, media freedom, media and gender. 